\title{
SPONTANEOUS RECOVERY RATES FOR UNILATERAL SIXTH NERVE PALSIES
}

\author{
ANTHONY J. KING ${ }^{1}$, EMMA STACEY ${ }^{2}$, GAIL STEPHENSON ${ }^{3}$ and ROGER B. TRIMBLE ${ }^{4}$
}

\section{SUMMARY}

Two hundred and thirteen patients with unilateral isolated sixth nerve palsies were assessed to determine what proportion of them underwent spontaneous recovery and over what period of time this recovery occurred. All were primary ophthalmic referrals from which trauma was excluded. In all, $78.4 \%$ of patients experienced spontaneous recovery of their palsy, $36.6 \%$ recovering by 8 weeks and $73.7 \%$ by 24 weeks. Only $16.4 \%$ failed to recover. Of this group, however, nearly $\mathbf{4 0} \%$ had serious underlying pathology accounting for their palsy.

Sixth nerve palsies are the commonest type of oculomotor palsy. ${ }^{1-3}$ Many series have concerned themselves with the underlying aetiologies of these palsies and the proportion of the total of oculomotor palsies that they account for. It is generally accepted that the greatest proportion of sixth nerve palsies are of unknown origin. ${ }^{1-3}$ Little work, however, has investigated the proportion of sixth nerve palsies that undergo spontaneous resolution and at what rate these palsies recover.

\section{METHODS}

Over a 16-year period, data have been collected on all patients presenting to St Paul's Eye Hospital, Liverpool, with the primary symptom of diplopia. These patients either attended the casualty department or were referred by their general practitioner. Secondary referrals from other ophthalmologists and other medical specialties were excluded, and trauma was also specifically excluded. The data available on patients included the diagnosis where known, the time to recovery and the length of follow-up. All patients continued to be followed up after recovery.

*This paper is dedicated to the memory of Roger B. Trimble, who died during its preparation.

From: ${ }^{1}$ University of Leicester; ${ }^{2}$ Department of Orthoptics, Walton Hospital, Liverpool; ${ }^{3}$ Department of Orthoptics, University of Liverpool, Liverpool; ${ }^{4}$ Walton Hospital, Liverpool, UK.

Correspondence to: Mr A. King, Lecturer in Ophthalmology, Leicester Royal Infirmary, Leicester LE2 7LX, UK.

\section{RESULTS}

A total of 213 unilateral isolated sixth nerve palsies were entered into the study. There were 116 left palsies and 97 right palsies. Fifty-two per cent of patients were males and $48 \%$ were females, and the mean age was 56.3 years (range 5-93 years) with a mean follow-up interval of 31.6 months (range 1-180 months).

One hundred and sixty-seven patients (78.4\%) underwent spontaneous recovery (mean recovery time 9.66 weeks), 35 patients $(16.4 \%)$ failed to recover and 11 patients $(5.2 \%)$ were lost to followup (Fig. 1). All those who recovered did so by $\mathbf{5 2}$ weeks. Of these, $46.7 \%$ (36.6\% of total) did so by 8 weeks, $84.4 \%$ (66.1\% of total) by 16 weeks and $94 \%$ (73.7\% of total) by 24 weeks (Table I, Figs. 2 and 3 ). The mean follow-up time for the recovered palsies was 30.9 months (range 1-180 months, median 25 months). None of the recovered palsies showed subsequent recurrence.

Thirty-five patients (16.4\%) failed to recover, 14 of whom had serious underlying pathology (Table II). The mean follow-up period for patients in this group $(n=21)$ with no identified pathology was 46 months (range 1-160 months). If the 2 patients who had a palsy for only 1 month are excluded, this follow-up increases to a mean of 50 months (range of 4-160 months).

Table I. Recovery rates for palsies

\begin{tabular}{cccc}
\hline \multirow{2}{*}{$\begin{array}{c}\text { Rate of recovery } \\
\text { (weeks) }\end{array}$} & \multirow{2}{*}{$\begin{array}{c}\text { No. recovered } \\
\text { (of total) }\end{array}$} & \multicolumn{2}{c}{ \% recovered } \\
\cline { 3 - 4 } & All palsies & Recovered group \\
\hline 8 & 78 & 36.6 & 46.7 \\
16 & 141 & 66.1 & 84.4 \\
24 & 157 & 73.7 & 94.0 \\
52 & 167 & 78.4 & 100.0 \\
\hline
\end{tabular}

Table II. Aetiologies of unrecovered palsies

\begin{tabular}{lc}
\hline Aetiologies of unrecovered palsies & Number \\
\hline Unknown & 21 \\
Tumour & 8 \\
Brain stem stroke & 3 \\
Carotid-cavernous fistula & 1 \\
Arnold-Chiari malformation & 1 \\
Aneurysm & 1 \\
Total & 35 \\
\hline
\end{tabular}




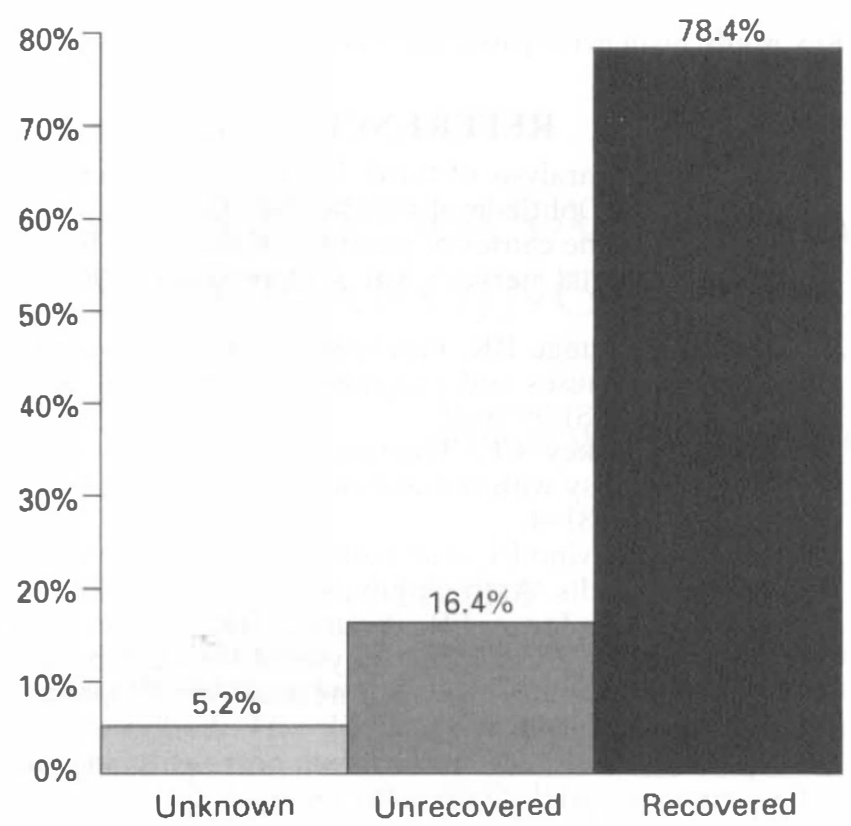

Fig. 1. Outcome of sixth nerve palsies.

\section{DISCUSSION}

In this study only patients with the primary complaint of diplopia were included, thus excluding all secondary referrals from other specialties, most importantly the neurosciences. We specifically also excluded traumatic palsies. Trauma was excluded because our aim was to determine the rate and proportion of recovery of spontaneous sixth nerve palsies of initially unknown aetiology; traumatic aetiologies therefore did not satisfy this requirement.

Estimates for the recovery rates of sixth nerve palsies have been made by only a few authors. Metz and Dickey in 1991 estimated that up to $70 \%$ of unilateral sixth nerve palsies recover spontaneously. Moster and Savino ${ }^{5}$ in 1984 showed an overall

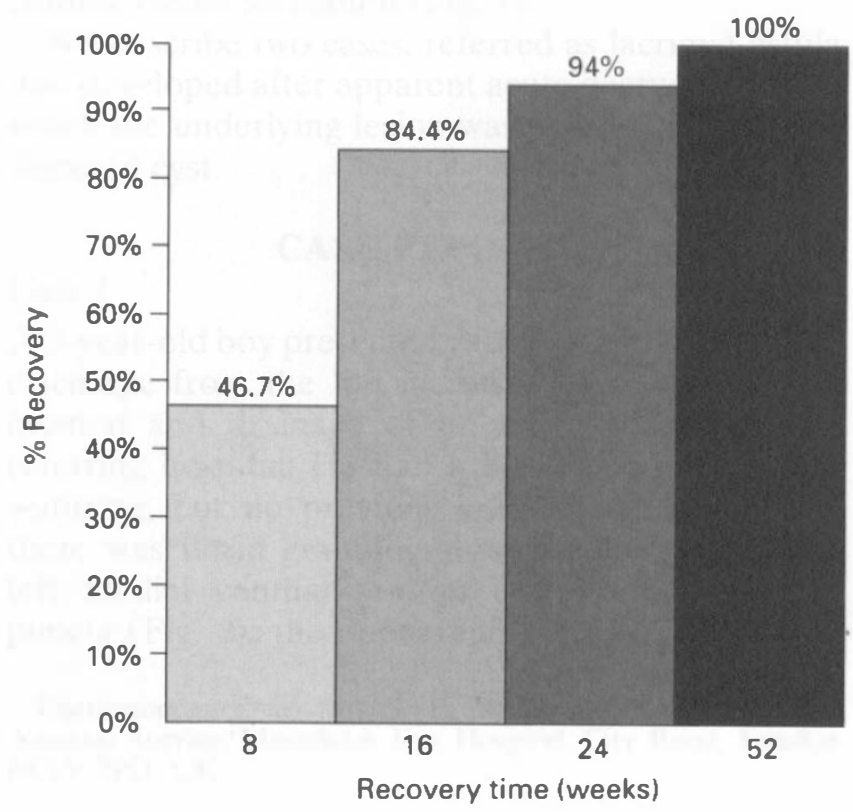

Fig. 2. Recovery time for recovered palsies.

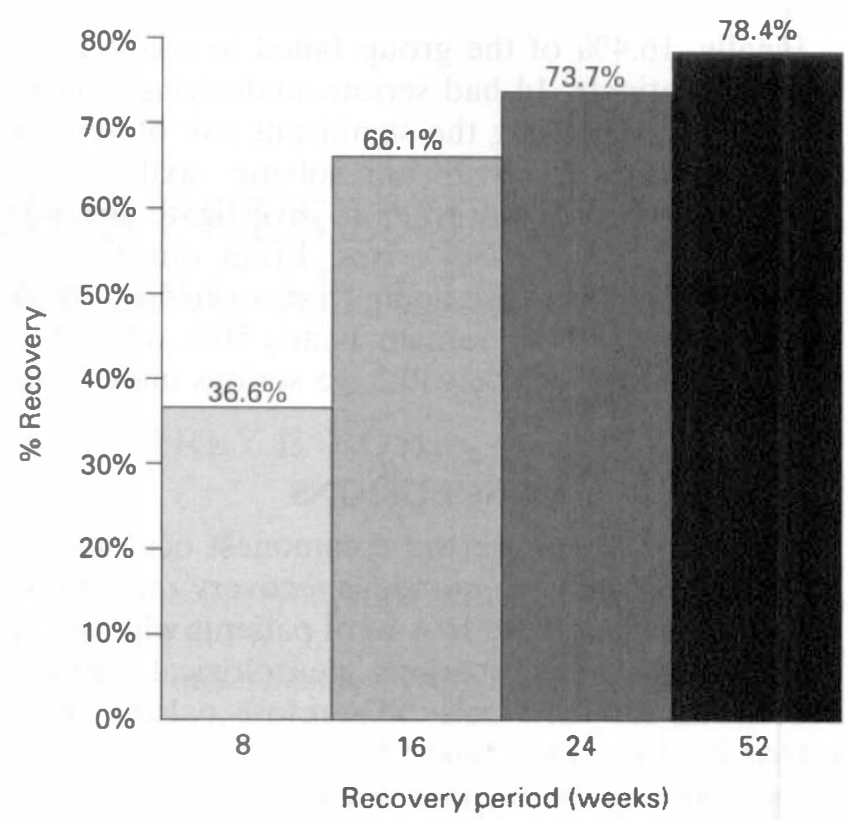

Fig. 3. Recovery rate for sixth nerve palsies.

recovery rate of $67 \%$ when traumatic causes were excluded. Rushe and Younge ${ }^{3}$ showed a recovery rate of $48.3 \%$ for the sixth nerves palsies in their series, which improved to $51.7 \%$ when traumatic causes were excluded. These recovery rates are substantially lower than ours; this difference may be explained by the different entry criteria for inclusion in the study, especially the exclusion of secondary referrals from our group. These patients often tend to have more serious underlying pathology, reducing their chance of recovery. Our study is based on a prospectively well-defined set of entry criteria, and for this defined general population we find a spontaneous recovery rate of $78.4 \%$. Richards et $a .^{6}$ in their study of 248 recovered palsies calculated a mean recovery time for a mixed group of palsies as 5.4 months. Our mean recovery time is 2.4 months for sixth nerve palsies; this possibly represents a higher proportion of sixth nerve palsies with an underlying vascular aetiology.

This study indicates the interval before recovery that occurs in the spontaneous recovery group. Overall $78.4 \%$ of palsies undergo spontaneous recovery, over a third of these doing so within the first 2 months and $94 \%$ by 6 months. None of the recovered palsies was associated with serious underlying pathology and none developed a recurrence, thus emphasising the low risk that a resolving palsy is associated with a serious pathology. Recently, a series of case reports by Volpe and Lessell ${ }^{7}$ showed that resolving sixth nerve palsies are occasionally associated with skull base tumours; the latest of the tumours presented 9 years after the initial sixth nerve palsy. We have no cases of this in our series to date. However, only patients with unresolving palsies or children and young adults had CT or MRI scans. 
Finally, $16.4 \%$ of the group failed to recover. Of these 35 patients, 14 had serious underlying pathology, thus emphasising the significant risk of serious disease associated with unresolving sixth nerve palsies. The question of when to investigate unresolving sixth nerve palsies arises. From our figures, $84.4 \%$ of those who are going to recover do so by 4 months. Of those who remain, nearly $50 \%$ will fail to resolve and nearly $20 \%$ will have serious underlying pathology.

\section{CONCLUSIONS}

Sixth nerve palsies are the commonest oculomotor palsy. They have a spontaneous recovery rate in our series of $78.4 \%$. Of the $16.4 \%$ of patients who fail to recover, $40 \%$ have serious neurological disease accounting for their palsy. Therefore palsies unresolved by 16 weeks should be fully investigated to exclude an underlying neurological aetiology.
Key words: Sixth nerve palsy, Recovery.

\section{REFERENCES}

1. Rucker CW. Paralysis of third, fourth and sixth cranial nerves. Am J Ophthalmol 1958;46:787-93.

2. Rucker CW. The causes of paralysis of the third, fourth and sixth cranial nerves. Am J Ophthalmol 1966;61: 1293-8.

3. Rushe JA, Younge BR. Paralysis of cranial nerves III, IV and VI: causes and prognosis in 1000 cases. Arch Ophthalmol 1981;99:76-9.

4. Metz HS, Dickey CF. Treatment of unilateral acute sixth nerve palsy with botulinum toxin. Am J Ophthalmol 1991;112:381-4.

5. Moster ML, Savino PJ, et al. Isolated sixth-nerve palsies in younger adults. Arch Ophthalmol 1984;102:1328-30.

6. Richards BW, Jones FR, Younge BR. Causes and prognosis in 4278 cases of paralysis of the oculomotor, trochlear and abducens cranial nerves. Am J Ophthalmol 1992;113:489-96.

7. Volpe NJ, Lessell S. Remitting sixth nerve palsy in skull base tumours. Arch Opthalmol 1993;111:1391-5. 